\title{
Screening for visual impairment in elderly patients with hip fracture: validating a simple bedside test
}

\begin{abstract}
Aims 1. To assess the prevalence of visual impairment in those patients who sustain proximal hip fracture after a simple fall. 2. To test the validity of a simple screening test to identify patients with visual impairment. Methods Patients on the orthopaedic rehabilitation ward recuperating from proximal hip fracture were recruited. The nurse screener and examining Ophthalmologist independently assessed the patients' distance visual acuity and visual field to confrontation. In addition, the nurse screener assessed for the presence of cataract in the red reflex and the examining Ophthalmologist performed a dilated slitlamp examination. On completion of the examination, the Ophthalmologist documented the cause(s) of any visual impairment found.
\end{abstract}

Results A total of 89 patients were assessed. In all, 29 patients (33\%) could be classified as visually impaired using the United States criteria and 52 patients $(58 \%)$ had a distance visual acuity of $6 / 18$ or worse in at least one eye. The test reliably identified those patients with visual impairment (sensitivity $94 \%( \pm 5 \%)$, specificity $92 \%( \pm 6 \%))$, but was less reliable at identifying those patients with potentially remedial visual impairment (sensitivity $70 \%( \pm 10 \%)$, specificity $92 \%( \pm 6 \%)$ ).

Conclusion The level of visual impairment in this group of patients is high and screening for visual impairment in the elderly with a history of falls is justified. We have demonstrated that a suitably trained member of the rehabilitation team can identify over $94 \%$ of those patients with impaired vision. We believe this
DM Squirrell', J Kenny², N Mawer', M Gupta', J West' ${ }^{1}$, ZI Currie', IM Pepper ${ }^{1}$ and CA Austin ${ }^{2}$

simple test should now be incorporated into the assessment of all patients requiring rehabilitation after a proximal hip fracture.

Eye (2005) 19, 55-59. doi:10.1038/sj.eye.6701421

Published online 7 May 2004

Keywords: proximal hip fracture; visual impairment; screening

\section{Introduction}

Visual impairment is an important independent predictor of the risk of hip fracture in elderly mobile patients. ${ }^{1-5}$ Epidemiological studies reveal that between 12 and $30 \%$ of persons aged 75 years and older in the United Kingdom have impaired vision ${ }^{6-8}$ and in many cases these patients are not in contact with either the hospital or community eye services. ${ }^{8,9}$ These data suggest that a significant number of patients who sustain a fractured neck of femur after a fall will therefore have impaired vision. They also suggest that in many patients the fall may have been a direct consequence of this visual impairment and furthermore the patient themselves may be unaware of this disability. There is a strong argument therefore for performing a visual assessment in all patients after hip fracture as part of a strategy to prevent further falls, regain independence, and improve the patients' overall wellbeing. We present the results of a study that was designed to validate the use of a simple screening test that would serve two purposes: 1 . identify all patients with visual impairment, 2 . identify those patients with a potentially remedial visual impairment who could then be referred on to the community or hospital eye services.
'Department of Ophthalmology Royal Hallamshire Hospital Glossop Road Sheffield, UK

${ }^{2}$ Department of Geriatric Medicine

Northern General Hospital Herries Road Sheffield, UK

Correspondence:

DM Squirrell Department of Ophthalmology

Royal Hallamshire Hospital

Glossop Road

Sheffield S10 2JF, UK

Tel: + $44(0) 1142713056$

Fax: + $44(0) 1142713682$

E-mail: Dsquirrell123@

aol.com

Received: 28 September 2003

Accepted: 28 November 2003

Published online: 7 May

2004

Funding: None.

Competing interests: None 


\section{Materials and methods}

All inpatients on the orthopaedic rehabilitation ward recuperating from surgical repair of a fractured neck of femur aged 75 years or over were approached by one of the investigators. Patients were invited to participate in the study if they had sustained their fracture after a simple 'slip, trip, and fall' and they scored seven or more on the abbreviated mental test score. If consenting, the patient's ocular history was recorded and a full ocular examination performed by an Ophthalmologist using slit-lamp biomicroscopy. A patient's vision was recorded using a $6 \mathrm{~m}$ Snellen chart that had been erected on the ward for this purpose. Visual acuity was first measured with both eyes open, with and without distance spectacles (if any were possessed). Visual acuity was then measured for each eye separately, first without spectacles and then with a pin-hole occluder. If the subject normally used spectacles for distance vision, the measurements were repeated, first with the spectacles and then with spectacles and a pin-hole occluder. The patient's visual field in each eye to confrontation was also assessed. On completion of the examination, the Ophthalmologist was asked to comment on the cause(s) of any visual impairment found.

The patients were also independently examined by a senior nurse from the rehabilitation team, who had undergone specific training in the eye clinic to enable him to perform this task. This training comprised two structured sessions with selected patients in which the nurse assessor was taught to assess visual acuity (with and without pin hole), visual fields to confrontation and to assess for cataract in the red reflex. Following these sessions, the nurse was seconded to the eye clinic for 1 week and joined one of the lead investigators (IMP) in assessing these three parameters of vision in all consenting patients attending the clinic. Only when both parties were confident in the nurse assessor's ability to assess these components of vision did patient recruitment commence. Following the same protocol as the Ophthalmologist, the nurse assessor recorded the patients' vision and assessed their visual field. He also used the direct ophthalmoscope to record the quality of the red reflex. The red reflex (from undilated pupils) was recorded as either full, reduced, or absent.

\section{Definitions of visual impairment used in this study}

The Ophthalmologist's examination was the 'gold standard' against which the nurse's screening examination was compared. For the purposes of this study, a patient was deemed to have impaired vision if they fulfiled the widely accepted United States criteria for impaired vision; ${ }^{10}$ (Presenting visual acuity both eyes open using usual spectacle correction (if any) worse than $6 / 12$ and/or significant visual field loss in both eyes). As there is also good evidence that disrupted stereopsis is an independent risk factor for falls in the elderly, $3,5,11$ any patient with a presenting visual acuity using usual spectacle correction (if any) worse than $6 / 18$ in either eye was also considered to have impaired vision.

For the purposes of this study, patients were deemed to have remedial visual impairment if they had uncorrected refractive error or a visually significant cataract (cataract responsible for a reduction in vision below 6/12 or symptomatic of glare if a posterior subcapsular cataract were present). In line with other published data, a patient was deemed to have uncorrected refractive error if their visual acuity could be improved using a pin-hole occluder by more than 1 line on the Snellen chart, from that achieved with their current spectacles (or unaided if none were used). ${ }^{7}$

\section{Ethical considerations}

Patient's consent was sought prior to the examination by the Ophthalmologist and nurse assessor. The visual assessment of each patient examined was forwarded to the rehabilitation team in overall charge of their care. In cases where a remedial cause of visual impairment was identified, patients were offered referral to the eye clinic or, in the case of uncorrected refracted error, were recommended to see a community Optometrist after their discharge from the ward.

\section{Statistics}

The ability of the nurse screener to identify those patients with visual impairment was assessed by examining the referrals that the nurse screener would have generated if one of two predetermined referral criteria were used. Criteria 1: distance visual acuity using both eyes open with usual spectacle correction (if any) worse than 6/12 or distance visual acuity worse than $6 / 18$ in either eye with usual spectacle correction (if any). Criteria 2: included those criteria outlined above, plus either of the following: cataract, uncorrected refractive error, or the presence of a homonymous hemianopia.

The ability of the nurse screener to identify those patients with potentially remedial visual impairment was assessed by examining the referrals that the nurse screener would have generated if he had only referred those patients who were deemed to have either uncorrected refractive error and/or visually significant cataract.

The sensitivity, specificity, and likelihood ratios were calculated for the ability of the screening test to detect each of: visual impairment as defined by criteria 1, visual 
impairment as defined by criteria 2 , potentially remedial visual impairment.

\section{Results}

In all, 89 patients were examined by both an Ophthalmologist and the nurse screener over an 8-month period. The mean age of patients recruited was 84 years (range 75-97). Of the participants, 74 were female and 15 were male. In all, based on the criteria defined above, 55 patients $(61 \%)$ were deemed to have impaired vision by the examining Ophthalmologist and 40 patients (45\%) were deemed to have potentially remedial visual impairment. The commonest causes of visual impairment were cataract or related pathology (23 patients), uncorrected refractive error (17 patients), and age-related macular degeneration (10 patients). In all, 52 patients $(58 \%)$ had a visual acuity of $6 / 18$ or worse in at least one eye. In the vast majority of patients, the refractive error was due to induced index myopia caused by early nuclear sclerotic cataracts.

\section{Ability of the nurse screener to identify those patients with impaired vision}

Testing patients' distance visual acuity (criteria 1) identified 52 of the 55 patients with impaired vision. The additional assessment of uncorrected refractive error, cataract in the red reflex, and a significant visual field defect (criteria 2) identified a further two patients with impaired vision. The sensitivity and specificity data and the corresponding likelihood ratios relating to the ability of the screening test to detect those patients with impaired vision are summarised in Table 1 . The use of criteria 1 achieved a sensitivity and specificity of 94 and $92 \%$, respectively. The use of criteria 2 was associated with a higher sensitivity than criteria $1(98 \%)$, but a lower specificity $(85 \%)$.

\section{Ability of the nurse screener to identify those patients with potentially remedial visual impairment}

Overall, the nurse screener identified only 28 of the 40 patients with potentially remedial visual impairment.
The corresponding sensitivity and specificity of this part of the test were 70 and 92\%, respectively (Table 1). The inadequacy of the test to identify early cataracts in the red reflex was responsible for the majority of those cases that the nurse screener missed. When the ability of the nurse screener to detect cataract in the red reflex was examined in isolation, this component of the test had a sensitivity of just $40 \%( \pm 15 \%$; $95 \%$ CI $)$ but achieved a specificity of $96 \%( \pm 4 \% ; 95 \% \mathrm{CI})$.

\section{Discussion}

This study represents a relatively small sample of elderly patients who sustained a fractured neck of femur after a simple fall. The selection was also biased in that only those patients with medical and or social needs that necessitated a period of rehabilitation after their surgery were examined. Those patients who did not require rehabilitation were not included as they were often discharged before the two sets of assessments could be undertaken. Our data are therefore not representative of all patients who sustain a fractured neck of femur. This probably explains why patients in our study had a higher incidence of visual impairment compared to other published data. ${ }^{3,12}$ With this caveat, our data do highlight the prevalence of visual impairment that may exist in elderly patients who sustain a fracture neck of femur after a simple fall.

Increasingly, identifying and treating visual impairment is recognised as an important preventative intervention in the elderly with a history of falls. ${ }^{13,14}$ Currently, however, it appears that very little provision is made to assess vision in these patients. We recently conducted a telephone survey of all units that care for patients after hip fracture in the surrounding four local strategic health authorities. Of the 17 units contacted, currently none performed a routine, objective assessment of their patients' visual status. This despite the evidence that impaired vision is an important aetiological factor in why many mobile elderly patients fall. This finding suggests that there is a need to develop a simple, reliable bedside tool that can be used to quickly assess the visual functioning of this group of patients.

Table 1 Results of the screening test to detect visual impairment and those patients with potentially remedial visual impairment

\begin{tabular}{|c|c|c|c|c|}
\hline & Sensitivity $(95 \%$ CI) & Specificity $(95 \% \mathrm{CI})$ & $\begin{array}{c}\text { Likelihood } \\
\text { ratio of a } \\
\text { positive result }\end{array}$ & $\begin{array}{c}\text { Likelihood } \\
\text { ratio of a } \\
\text { negative result }\end{array}$ \\
\hline Detection of visual impairment (criteria 1) & $94 \%(89-99 \%)$ & $92 \%(86-98 \%)$ & 12 & 0.06 \\
\hline Detection of visual impairment (criteria 2) & $98 \%(95-100 \%)$ & $85 \%(78-92 \%)$ & 7 & 0.02 \\
\hline Detection of potentially remedial visual impairment & $70 \%(60-80 \%)$ & $92 \%(86-98 \%)$ & 9 & 0.3 \\
\hline
\end{tabular}


We have demonstrated that a member of staff from the rehabilitation team can be trained to reliably test many aspects of a patient's visual status. Using a Snellen chart at 6 metres and a direct ophthalmoscope, the assessment undertaken by the nurse screener was highly sensitive and specific in identifying those patients with visual impairment. In particular, measuring patients, distance visual acuity alone identified $94 \%$ of those patients who were deemed by the ophthalmologist to have impaired vision. This figure increased to over $98 \%$ if the nurse screener also assessed pinhole visual acuity and examined for cataract in the red reflex. This was achieved without unduly affecting the specificity of the test.

With a sensitivity of just $70 \%$, the assessment undertaken by the nurse screener was not reliable at identifying those patients with potentially remedial visual impairment. The failure of the technique to identify nuclear sclerotic cataracts in the red reflex was largely responsible for this deficiency, but this component of the assessment was not without its value. The high specificity of this part of the test indicates that, when the nurse did detect a shadow in the red reflex, a visually significant cataract was almost certainly present.

It is well recognised that conventional tests of vision, such as Snellen visual acuity, often greatly underestimate the actual level of visual impairment in older adults. ${ }^{15-17}$ West $e t a l^{18}$ reported that if more sophisticated tests of visual function such as contrast sensitivity, glare recovery, and dark acuity tests were used, then up to $60 \%$ of elderly subjects assessed with these tests failed them, compared to only $20 \%$ of the same cohort who failed standard high-contrast (Snellen) visual acuity tests. Similarly, it is now well recognised that standard clinical tests of a patient's visual field may also underestimate the peripheral visual field problems in this group of patients. ${ }^{19}$ It is therefore very likely that our results underestimate the actual visual problems experienced by the patients we examined. This matters as it is now well accepted that poor vision has a number of wide-reaching consequences. Visual impairment is recognised to be an important independent predictor of the risk of hip fracture in elderly mobile patients. ${ }^{1-5}$ In particular, it has been demonstrated that vision is an important influence on postural stability in the elderly, particularly on compliant surfaces such as carpets. ${ }^{20,21}$ Furthermore, visual impairment impacts on a wide range of objective and subjective measures of functional status, including those measures which are not actually vision dependant, such as psychological well being. ${ }^{16,18,22-25}$

One of the principle aims of the current study was to develop a simple bedside screening test that could be incorporated into the rehabilitation package offered to patients who fall sustaining a fractured neck of femur. While not without its limitations, high-contrast Snellen visual acuity is still deemed to be a useful indicator of the ability of an older patient to perform a range of visiondependant daily living tasks. ${ }^{16,26}$ Within the confines of a simple bedside screening test, we feel that Snellen visual acuity and visual field to confrontation remain valid tools for this purpose. That $61 \%$ of patients examined in our study failed these unsophisticated tests only serves to emphasise the level of visual morbidity that may exist in this highly selective group of patients.

We believe that this study demonstrates two important points. It illustrates the level of visual impairment that may exist in this group of patients, and it demonstrates the relative ease with which these patients can be screened for visual impairment. So what should the rehabilitation teams now be doing for this group of patients? We recommend that, at the very least, the distance visual acuity of all patients who fall should be examined. This simple measure will identify the vast majority of patients with impaired vision. The additional assessment of pinhole visual acuity and cataract in the red reflex will further increase the pick-up rate. As the aetiology of the visual impairment in many patients is either not remedial to treatment, or is simply uncorrected refractive error, we believe that direct referral to the hospital eye service on finding impaired vision in this group of patients is not warranted. In most cases, an assessment by an Optometrist would be more beneficial. As there is good evidence that even those patients with a nonremedial cause for their visual impairment would benefit from an assessment in the use of low vision aids, referral to an Optometrist with experience in this field would be ideal. ${ }^{27}$ The one exception to this recommendation would be patients in whom the nurse screener detected a shadow in the red reflex. In this selected group of patients, direct referral to the hospital eye service for consideration of cataract surgery is probably justified.

\section{Conclusion}

We found that almost two-thirds of the cohort examined failed the unsophisticated tests of visual function that we employed. It is known that these vision tests underestimate the extent of visual impairment in older adults, and thus our results are likely to represent an underestimation of the actual problems experienced by this group of patients. This and other published data demonstrate that visual impairment is common in the elderly with a history of falls, and assessment of the visual status of these patients is therefore worthwhile. A suitably trained member of the rehabilitation team identified over $94 \%$ of those patients with impaired vision, simply by assessing a patient's distance vision. This figure increased to over $98 \%$ if the assessment also 
included an examination for cataract in the red reflex, uncorrected refractive error, and visual field defects. This simple assessment would complete the holistic package of care that we believe should be offered to all elderly patients recuperating from a proximal hip fracture after a simple fall. It perhaps should also be extended to all patients who fall, regardless of whether they suffer injury or not.

\section{References}

1 Dargent-Molina P, Favier F, Grandjean H, Bandoin C, Schott AM, Hausherr E et al. Fall related factors and risk of hip fracture: the EPIDOS prospective study. Lancet 1996; 348: 145-149.

2 Cummings SR, Nevitt MC, Browner WS, Stone K, Fox K, Ensrud KE et al. Risk factors for hip fracture in white women. N Engl J Med 1995; 332: 767-773.

3 Ivers RQ, Norton R, Cumming RG, Butler M, Campbell J. Visual impairment and risk of hip fracture. Am J Epidemiol 2000; 152: 633-639.

4 Ivers RQ, Cumming R, Mitchell P. Poor vision and risk of falls and fractures in older Australians: the Blue Mountains Eye study. N S W Public Health Bull 2002; 13: 8-10.

5 Felson DT, Anderson JJ, Hannan MT, Milton RC, Wilson PW, Kiel DP. Impaired vision and hip fracture. The Framingham Study. J Am Geriatr Soc 1989; 37: 495-500.

6 Evans JR, Fletcher AE, Wormald RP, Na S, Stirling S, Smeeth $\mathrm{L}$ et al. Prevalence of visual impairment in people aged 75 years and older in Britain: results from the MRC trial of assessment and management of older people in the community. Br J Ophthalmol 2002; 86: 795-800.

7 Van der pols JC, Bates CJ, McGraw PV, Thompson JR, Relicher M, Prentice A et al. Visual acuity measurements in a national sample of British Elderly people. $\mathrm{Br} J$ Ophthalmol 2000; 84: 165-170.

8 Reidy A, Minasain DC, Vafidis G, Joseph J, Farrow S, Wu J et al. Prevalence of serious eye disease and visual impairment in a north London population: population based, cross sectional study. BMJ 1998; 316: 1643-1646.

9 Wormald RP, Wright LA, Courtney P, Beaumont B, Haines AP. Visual problems in the elderly and implications for services. BMJ 1992; 304: 1226-1229.

10 Rubin GS, Wesl SK, Munoz B, Bandeen-Roche K, Zeger S, Schein $\mathrm{O}$ et al. A comprehensive assessment of visual impairment in a population of older Americans. Invest Ophthalmol Vis Sci 1997; 38: 557-568.

11 Nevitt MC, Cummings SR, Kidd S, Black D. Risk factors for non syncopal falls: a prospective study. JAMA 1989; 261: 2663-2668.
12 Cox A, Blaikie A, Mac Ewan CJ, Jones D, Thompson K, Holding D et al. Ophthalmic assessment of elderly patients with hip fracture. Data presented at the Annual Congress of the Royal College of Ophthalmologists. Birmingham, May 2003.

13 Tinetti ME. Preventing falls in elderly persons. N Engl J Med 2003; 348: 42-49.

14 Woolf $\mathrm{AD}$, Akesson K. Preventing fractures in elderly people. BMJ 2003; 327: 89-95.

15 Rubin GS, Roche KB, Prasada-Rao P, Fried LP. Visual impairment and disability in older adults. Optom Vis $\mathrm{Sci}$ 1994; 71: 750-760.

16 West SK, Munoz B, Rubin GS, Schein OD, Bandeen-Roche $\mathrm{K}$, Zeger $\mathrm{S}$ et al. Function and visual impairment in a population-based study of older adults.

The SEE project. Invest Oophthalmol Vis Sci 1997; 38: $72-82$.

17 Haegerstrom-Portney G, Schneck ME, Brabyn JA. Seeing into old age: vision function beyond acuity. Optom Vis Sci 1999; 76: 141-158.

18 West CS, Gildengorin G, Haegerstrom-Portney G, Schnek $\mathrm{ME}$, Lott L, Brabyn JA. Is vision function related to physical functional ability in older adults? J Am Geriatr Soc 2002; 50: 136-145.

19 Ball K, Owsley C, Beard B. Clinical visual perimetry underestimates peripheral visual field problems in older adults. Clin Vision Sci 1990; 5: 113-125.

20 Turano K, Rubin GS, Herdman SJ, Chee E, Fried LP. Visual stabilization of posture in the elderly: fallers $v$ s non fallers. Optom Vis Sci 1994; 71: 761-769.

21 Lord SR, Clark RD, Webster IW. Visual acuity and contrast sensitivity in relation to falls in an elderly population. Age Ageing 1991; 20: 175-181.

22 Kuyk T, Elliot JL, Fuhr PS. Visual correlates of mobility in real world settings in older adults with low vision. Optom Vis Sci 1998; 75: 538-547.

23 Carabellese C, Appollonia I, Rozzini R, Bianchetti A, Frisoni $\mathrm{CB}$, Frattola L et al. Sensory impairment and quality of life in a community elderly population. J Am Geriatr Soc 1993; 41: 401-407.

24 Rovner BW, Zisselman PM, Shmuely-Dulitzki Y. Depression and disability in older people with impaired vision: a follow up study. J Am Geriatr Soc 1996; 44: 181-184.

25 Lee PP, Spritzer K, Hays RD. The impact of blurred vision on functioning and well being. Ophthalmology 1997; 104: 390-396.

26 McClure ME, Hart PM, Jackson AJ, Stevenson MR, Chakravarthy U. Macular degeneration: do conventional measurements of impaired visual function equate with visual disability? Br J Ophthalmol 2000; 84: 244-250.

27 Margrain TH. Minimising the impact of visual impairment. BMJ 1999; 318: 1504. 